\title{
A CT Scan Study Showing Prevalence of Haller Cells in Patients with Sinonasal Complaints
}

\author{
Raag Reeti ${ }^{1}$, Md Jawed Akhtar ${ }^{2}$, Avanish Kumar ${ }^{\oplus 3}$, Rishi Mani Srivastava ${ }^{\oplus 4}$ \\ ${ }^{1}$ Tutor, Department of Anatomy, Indira Gandhi Institute of Medical Sciences, Patna, Bihar, India, ${ }^{2}$ Assistant Professor, Department of Anatomy, Indira Gandhi Institute \\ of Medical Sciences, Patna, Bihar, India, ${ }^{3}$ Professor and Head, Department of Anatomy, Indira Gandhi Institute of Medical Sciences, Patna, Bihar, India, ${ }^{4}$ Rishi Clinic and \\ Research Centre, Patna, Bihar, India.
}

\section{Abstract}

Background: Anterior ethmoid cells that extend into the maxillary sinus roof are known as Haller cells. They are commonly seen on the floor of the orbit. They may cause sinusitis symptoms by blocking the infundibulum, may get infected and also sometimes complicate the Functional Endoscopic Sinus Surgery (FESS). The present study was undertaken to determine the prevalence of Haller cells on CT scans in patients having sino-nasal complaints. Subjects and Methods : This was a descriptive observational study carried out on 150 patients who presented with various sino-nasal complaints and underwent a CT Scan in the Department of Radiodiagnosis, Bangur Institute of Neurosciences, Kolkata. Their CT scans were studied retrospectively for the presence of Haller cells. Radiological variations data were summarized by routine descriptive statistics namely counts and percentages for categorical variables. Fisher's Exact Tests and were applied to calculate the 'p' value to find out any statistically significant difference between males and females. Results: Haller cells were found in 12\% (18 cases) in the present study, $5.33 \%$ in males and $6.67 \%$ in females. 'p' value in this case was 0.616 on applying Fisher's Exact test. Conclusion: Anatomical variations of the paranasal sinus region like Haller cells are quite common and they must be searched for by the surgeons planning any endoscopic sinus surgery. This study attempted to provide the prevalence of the Haller cells in Eastern India which will definitely help the FESS surgery and its outcomes.

Keywords: Infra orbital cells, Maxillary sinus, Functional Endoscopic Sinus Surgery.

Corresponding Author: Md Jawed Akhtar, Assistant Professor, Department of Anatomy, Indira Gandhi Institute of Medical Sciences, Patna, Bihar, India.

E-mail: drjawed2k@gmail.com

Received: 02 October 2020

Revised: 25 November 2020

Accepted: 03 December 2020

Published: 24 December 2020

\section{Introduction}

Haller cells are ethmoidal air cells that extend into the regions of orbit and maxillary sinus. They are present near the lateral border of the infundibulum, on the roof of the maxillary sinus. They are named after anatomist Albert Von Haller. He first identified this ethmoidal pneumatization of the orbital floor in 1765 . Haller cells are present medial to the infraorbital canal and lateral to the nasolacrimal duct. They are also named orbito-ethmoidal cells or maxillo-ethmoidal cells as they are the anterior extensions of ethmoidal sinuses into the orbital floor or superior aspect of the maxillary sinus. Thus, Haller's cells are extramural ethmoidal cells that pneumatize into the orbital floor inferiorly and extend from the ethmoid labyrinth, below the ethmoid bulla, towards the interior of the maxillary sinus. They are usually seen on the floor of the orbit at the level between the inferior and medial rectus muscles of the eyeball. They can very often compromise the infundibulum. They have been implicated in maxillary sinus diseases, dehiscence of the orbital floor, pain in the orofacial region and others. They may obstruct the nasal cavity, disturbed nasal breathing, headache, chronic cough and mucoceles. They can also cause difficulties during endonasal procedures.

The present study was aimed to find the prevalence of Haller cells which will help the clinicians to understand the disease processes in a much efficient manner and to proceed accordingly. This will also help the surgeons performing endoscopic sinus surgeries to have a better knowledge of the prevalence of Haller cells which will lead to better surgical outcomes. $^{[1]}$

\section{Subjects and Methods}

A descriptive observational study was conducted in the Department of Anatomy, IPGME\&R, Kolkata for a period of 1 year from March 2015 to February 2016 after obtaining 
ethical clearance from the Institute's Ethical Committee. It mainly focused on the CT scan anatomy of the paranasal sinus region to find out the prevalence of Haller cells. CT scans of 150 patients who attended the Department of Radiodiagnosis, Bangur Institute of Neurosciences, Kolkata were taken after studying their history and complaints. Being a descriptive study, a formal sample size calculation was not done. It was proposed to recruit 150 subjects over a period of 1 year.

The CT scans of the patients fulfilling the inclusion and exclusion criteria were then collected for the present study to determine the variation in the prevalence of Haller cells.

\section{Inclusion criteria}

Patients with sino-nasal symptoms who underwent a CT scan.

\section{Exclusion criteria}

CT scans that were revealing - any sino-nasal disease which caused any type of bony deformity or destruction, polyp, nasopharyngeal tumors, $\mathrm{H} / \mathrm{O}$ trauma or injury (as obtained from the records), $\mathrm{H} / \mathrm{O}$ previous surgeries that involved the nasal cavity and paranasal sinuses (as obtained from the records). The scan was performed by keeping the patient in the prone position. Axial sections were taken from the tip of the nose to the roof of the frontal sinus. Coronal sections were taken from the tip of the nose to the roof of the sphenoid sinus perpendicular to the hard palate. Sagittal sections were also taken after reconstruction.

The prevalence of Haller cell was seen on the CT scans and the results were analysed as a percentage. Fischer's Exact Test was applied to calculate the 'p' value to find out any statistically significant difference between males and females.

\section{Results}

Haller cells were found in $12 \%$ of cases in the present study, $5.33 \%$ in males and $6.67 \%$ in females. [Table $1 \&$ Figure 1,2].

Fisher's Exact test was applied and 'p'=0.616 which was statistically not significant but was clinically significant.

A bar Diagram was also made in this case. In this bar diagram, Series 1 represents male cases and Series 2 represents female cases. The $\mathrm{X}$-Axis represents several cases and $\mathrm{Y}$-axis represents the presence and absence of Haller cells.

\section{CT Scan Image [Figure 2]}

\section{Discussion}

The presence of this infraorbital cell or Haller cell was noted in $12 \%$ of cases in the present study. It was observed to be varying between $1 \%$ to $53 \%$ in different studies conducted on anatomical variations of PNS. So, the presence of Haller

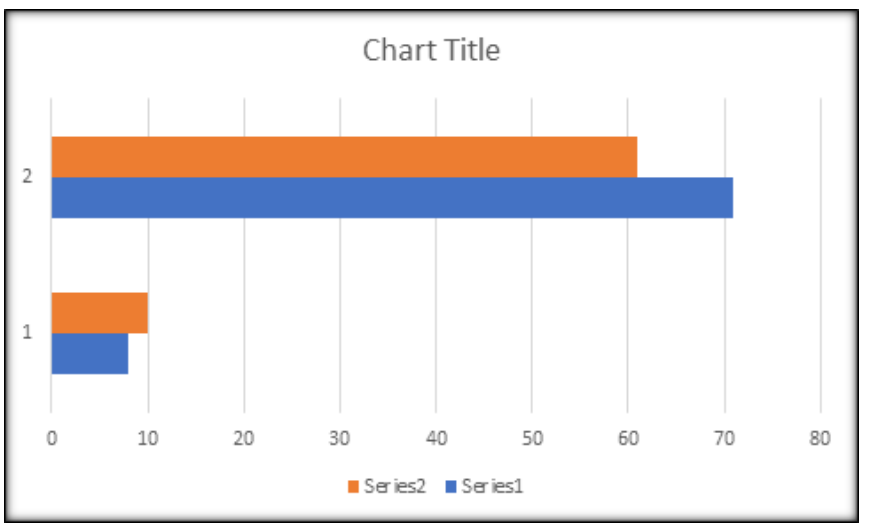

Figure 1: 1: Distribution of Haller cells in males and females.

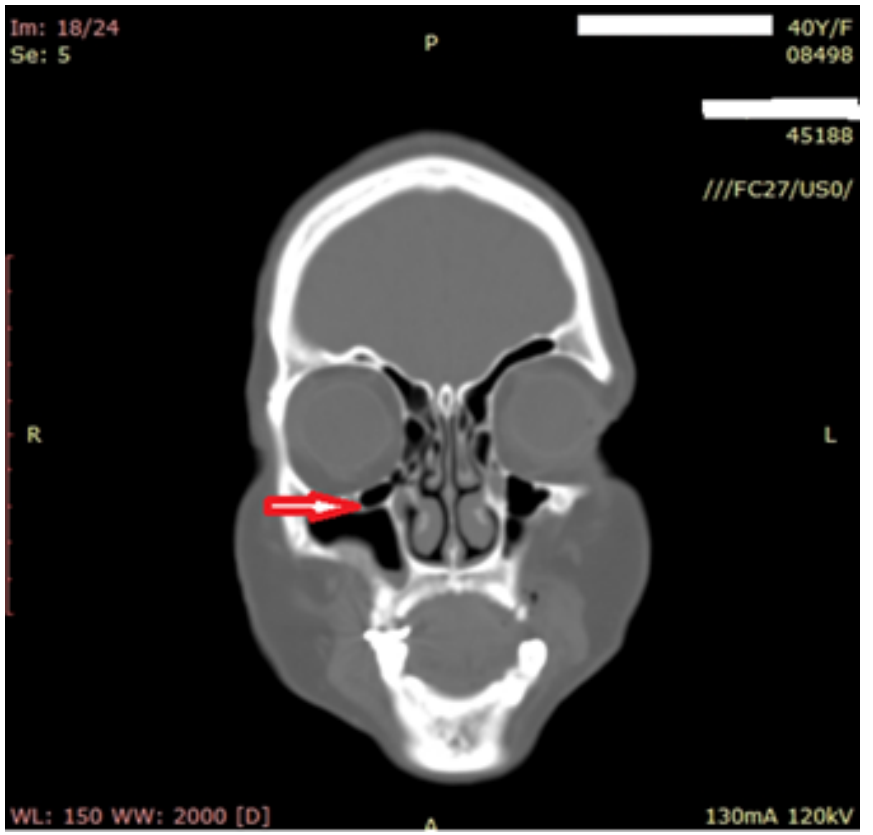

Figure 2: CT of PNS - Coronal section showing Haller cell

cells revealed such a wide variation that it required careful observation while studying the CT scans. K Dua et al, ${ }^{[2]}$ in 2005 studied the CT scans of 50 patients with chronic sinusitis to observe the anatomical variations of paranasal sinuses and the stomatal complex. They found Haller cells in $16 \%$ of cases. A cross-sectional study was conducted at NKP Salve Institute of Medical Sciences, Nagpur by Nitin V Deosthale et al, ${ }^{[3]}$ in 2014. They performed 'Nasal Endoscopy', and 'Computed Tomography' to find out the prevalence of anatomical variations of the nose and paranasal sinuses in Chronic Rhinosinusitis (CRS). They further correlated the 
Table 1: Distribution of Haller cells in males and females.

\begin{tabular}{|c|c|c|c|}
\hline Gender & $\begin{array}{l}\text { Study cases with } \\
\text { Haller cell }(\%)\end{array}$ & $\begin{array}{l}\text { Study cases without Haller } \\
\text { cell }(\%)\end{array}$ & Total (\%) \\
\hline Male & $8(5.33 \%)$ & $71(47.33 \%)$ & $79(52.67 \%)$ \\
\hline Female & $10(6.67 \%)$ & $61(40.67 \%)$ & $71(47.33 \%)$ \\
\hline Total & $18(12 \%)$ & $132(88 \%)$ & $150(100 \%)$ \\
\hline
\end{tabular}

above-mentioned investigations modalities and also detected the association of such variations in Chronic Rhinosinusitis. They observed Haller cells by $16 \%$. Sheetal D et al, ${ }^{[4]}$ in 2011 performed a study on 45 patients to correlate the findings of CT and endoscopy in FESS, the anatomical abnormalities and the mucosal changes in patients with chronic rhinosinusitis (CRS) and the reliability and validity of CT scan in the management of CRS. They underwent a CT scan of PNS preoperatively and then performed FESS. They found Haller cells in $14 \%$ of cases. The accuracy of limited CT with the full CT was compared by Tantilipikorn $\mathrm{P}$ et al, ${ }^{[5]}$ in 2009 . They observed Haller cells in $12.5 \%$ of cases. H Mamatha et al in $2010,{ }^{[6]}$ studied the stomatal complex, its variations and applied anatomical aspects. $40 \mathrm{CT}$ films of paranasal sinuses were collected from the department of ENT to study their coronal sections. Haller cells were present in 7 (17.5\%) cases. A study was performed by Priyanka Chakraborty et al, ${ }^{[7]}$ in 2016 in Sir Sunderlal Hospital, Banaras Hindu University, Varanasi. They included 82 patients in the study. They were subjected to CT scans after being diagnosed as cases of chronic rhinosinusitis based on history and endoscopy of the nasal cavity. They found Haller cells in $9.7 \%$ of cases. A study was conducted at the Aga Khan University Hospital, Karachi by Mohammad Adeel et al, ${ }^{[8]}$ in 2013. CT scans of 77 patients were studied. Haller cells were observed in $9.1 \%$ of cases. Arslan et al, ${ }^{[9]}$ conducted a study on patients who had to undergo functional endoscopic sinus surgery for the treatment of chronic rhinosinusitis. They studied the CT scans of 200 patients with chronic sinusitis and analyzed them to determine the prevalence of anatomical variations. They observed Haller cells in $6 \%$ of cases. Mazza D et al, ${ }^{[10]}$ in 2007 selected 100 patients who were 45 caucasian women and 55 men aged between 18 and 70 years and performed a 64-slice $\mathrm{CT}$ evaluation to find out some important anatomic variants of paranasal sinuses. Haller cells were observed in $5 \%$ of cases. Chandel NS et al, ${ }^{[11]}$ in 2015 evaluated the anatomical variation of PNS by CT scan and compared and analyzed congenital anatomical variations of paranasal sinuses in both sexes and determined the frequency of such variations. Haller cells were found in $5 \%$ of cases. Benjaporn et al in 2005 , $^{[12]}$ performed their study on adult Thai patients and studied the anatomical variations of the paranasal sinuses and the lateral nasal wall. They studied $88 \mathrm{CT}$ scans of paranasal sinuses and orbits retrospectively. Haller cell was found in $24 \%$. Robinson
$\mathrm{M}$ et al, ${ }^{[13]}$ in 2010 studied museum skulls of Melanesians by a non-random sampling which was not studied previously and observed the variations in the paranasal sinuses. Haller cells were found in $31.7 \%$ of cases. Stackpole S A et al in 1997, [14] conducted a study to show that the Haller cell was anatomically relevant in sinusitis. They observed the Haller cells to be an extension of the pneumatization of ethmoid sinus along the roof of the maxillary sinus. They are also found responsible for causing sinusitis because they can cause the narrowing of the infundibulum. They selected 154 patients and studied their CT scans on coronal sections and evaluated the role of Haller cells as a cause of sinusitis. Haller cells were present in 34\% of patients. They graded them as small, medium, or large and correlated that there was evidence of sinusitis radiologically in those patients. There was a statistically significant increase in the mucosal disease of the maxillary sinus. There were $45.8 \%$ of patients with mucosal disease with medium or large Haller cells and $28.9 \%$ with small cells. Hence, it was concluded that large Haller cells may be an important factor in causing sinusitis. Maru Y K et al, ${ }^{[15]}$ in 2001 studied the sinonasal CT scan of 61 patients with symptoms of chronic sinusitis and found Haller cells in $36.1 \%$ cases. Liu X et al, ${ }^{[16]}$ in 1999 studied coronal CT scans of 297 individuals and found out the relation between the stomatal complex variations and chronic sinusitis. They observed Haller cells in only $1 \%$ of cases. Kate Sarika P et al in $2015,{ }^{[17]}$ conducted a study at Medical colleges and Hospitals in Pune. 90 patients who were referred for a CT scan of PNS were included. They performed unenhanced CT of the PNS in the coronal plane which was complemented by axial views. They found Haller cell only in 1 patient out of 90 . Perez Pinas et al, ${ }^{[18]}$ in 2000 studied 110 CTs of sino nasal region of Spanish population. Patients with suspected inflammatory sinus pathology were included. Haller cells were found in $2.7 \%$ of cases. Kayalioglu $\mathrm{G}$ et al, ${ }^{[19]}$ in 2000 selected 82 adult patients who did not have any sinus pathology and 90 adult patients who had sinus disease and performed high resolution computed tomography of paranasal sinuses and observed Haller cells in $3.65 \%$ cases. D. Krishna Chaitanya et al in $2015,{ }^{[20]}$ conducted a study in Department of Radiology in Kamineni Institute of Medical Sciences, Narketpally, Andhra Pradesh on 100 patients with suspected nasal pathology. They observed Haller cells in 53\% of cases. ${ }^{[21]}$ 


\section{Conclusion}

The present study attempted to find out the prevalence of Haller cells in the adult population. The knowledge of this variation will help the endoscopic surgeons to avoid complications during surgery. The data provided will act as a guide for future researchers in this field.

\section{References}

1. S S, editor. Jafek BW. Gray's anatomy: the anatomical basis of clinical practice; 2008.

2. Dua K, Chopra H, Khurana AS, Munjal M. CT scan variations in chronic sinusitis. Indian J Radiol Imaging. 2005;15(3):315315. Available from: https://dx.doi.org/10.4103/0971-3026. 29144.

3. Deosthale NV, Sonali P, Singh B, Hrkare VV, Dhoke PR, Dhote KS. Anatomical variations of nose and paranasal sinuses in chronic rhinosinusitis. People's. People's J Sci Res. 2014;7(2):1-7.

4. Sheetal D, Devan PP, Manjunath P, Martin P, Satish K, Sreekantha, et al. CT PNS- Do we really require before FESS? J Clin Diag Res. 2011;5(2):179-181.

5. Tantilipikorn P, Churojana A, Chiewwit P, Phuttharak W, Lerdlum S, Aeumjaturapat S. The accuracy of limited CT in the evaluation of chronic rhinosinusitis and for endoscopic sinus surgery : A multicenter study. Siriraj Med J. 2009;61(1):3-7.

6. Mamatha H. Variations of ostiomeatal complex and its applied anatomy: a CT scan study. Indian J Sci Technol. 2010;3(8):904-907. Available from: https://dx.doi.org/10. 17485/ijst/2010/v3i8.17.

7. Chakraborty P, Jain RK. Radiologic variations of ose and paranasal sinuses: A CT based study. JMSCR. 2016;4(5):10536-10577. Available from: http://dx.doi.org/10. $18535 / \mathrm{jmscr} / \mathrm{v} 4 \mathrm{i} 5.25$.

8. Adeel M, Rajput MS, Akhtar S, Ikram M, Arain A, Khattak YJ. Anatomical variations of nose and paranasal sinuses: CT scan review. J Pak Med Assoc. 2013;63(3):317-319.

9. Arslan H, Aydınlıŏlu A, Bozkurt M, Egeli E. Anatomic variations of the paranasal sinuses: CT examination for endoscopic sinus surgery. Auris Nasus Larynx. 1999;26(1):3948. Available from: https://dx.doi.org/10.1016/s0385-8146(98) 00024-8.

10. Mazza D, Bontempi E, Guerisi A, Elonti S, Cipolla G, Perrone A, et al. Paranasal sinuses anatomic variants : 64- slice CT evaluation. Inerve Stomatol. 2007;56(6):311-329.

11. Chandel NS, Gupta R, Vyas MM. Computerized Tomographic Evaluation of Antomical Variations of Paranasal Sinus \& Nose. National J Med Den Res. 2015;4(1):48-72. Available from: https://dx.doi.org/10.18203/2320-6012.ijrms20161975.

12. Nitinavakarn B, Thanaviratananich S, Sangsilp N. Anatomical variations of the lateral nasal wall \& paranasal sinuses: A CT study for endoscopic sinus surgery(ESS) in Thai patients. J Med Assoc Thai. 2005;88(6):763-771.

13. Robinson M, Donlon D, Harrison H, Houang M, Stammberger $\mathrm{H}$, Wolf G. Variations of the paranasal sinuses in Melanesians as observed by CT. Rhinology. 2010;48(1):11-18. Available from: https://doi.org/10.4193/rhin09.083.

14. Stackpole SA, Edelstein DR. The Anatomic Relevance of the Haller Cell in Sinusitis. Am J Rhinol. 1997;11(3):219-224. Available from: https: //dx.doi.org/10.2500/105065897781751910.

15. Maru YK, Gupta V. Anatomic variations of the bone in sinonasal CT. Indian J Otolaryngol Head Neck Surg. 2001;53:123-151. Available from: https://dx.doi.org/10.1007/ BF02991504.

16. Liu X, Zhang G, Xu G. Anatomic variations of osteomeatal complex \& their correlation with chronic sinusitis : CT evaluation. Zhonghua Er Bi Yan Hou Ke Za Zhi. 1999;34(3):143-149.

17. P KS, ND M, BH B. Anatomic variations of paranasal sinuses in patients with chronic sinusitis and their correlation with CT scan study. Int J Curr Res. 2015;7(15):49-55.

18. Pinas IP, Sabate J, Carmona A, Catalina-Herrera CJ, Castellanos JJ. Anatomical variations in the human paranasal sinus region studied by CT. J Anat. 2000;197(pt2):221-227. Available from: https://dx.doi.org/10.1046/j.1469-7580.2000. 19720221.x.

19. Kayalioglu G, Oyar O, Govsa F. Nasal cavity and paranasal sinus bony variations: a computerized tomographic study. Rhinology. 2000;38(3):108-121.

20. Chaitanya DK, Suseelamma D, Singh V. Anatomical variations of paranasal air sinuses - A CT scan study. J Anat Soc India. 2015;64(1):87-90. Available from: https://dx.doi.org/10.1016/ j.jasi.2015.04.017.

21. Talaiepour AR, Sazgar AA, Bagheri A. Anatomic variations of the paranasal sinuses on CT scan images. J Dentistry Tehran Univ Med Sci. 2005;2(4):142-146.

Copyright: (C) the author(s), 2020. It is an open-access article distributed under the terms of the Creative Commons Attribution License (CC BY 4.0), which permits authors to retain ownership of the copyright for their content, and allow anyone to download, reuse, reprint, modify, distribute and/or copy the content as long as the original authors and source are cited.

How to cite this article: Reeti R, Akhtar MJ, Kumar A, Srivastava RM. A CT Scan Study Showing Prevalence of Haller Cells in Patients with Sinonasal Complaints. Acad. Anat. Int. 2020;6(2):92-95.

DOI: dx.doi.org/10.21276/aanat.2020.6.2.20

Source of Support: Nil, Conflict of Interest: None declared. 